\title{
Norwegian Business Professionals' Need for and Use of English as a Business Lingua Franca (BELF) in Multinational Corporations
}

\begin{abstract}
English is now the corporate language of many multinational corporations (MNCs) worldwide. However, when English is used as a shared language resource, a lingua franca, its use may be both fluid and local, and the characteristics of its local use should then be explored. This article therefore investigates English used as a Business Lingua Franca (BELF) in MNCs in Norway through task-based interviews with Norwegian business professionals about their need for and use of BELF. The findings indicate that business professionals need to use it frequently, and for both routine and more complex tasks, like demanding business meetings. While getting the job done was paramount to all, several associated NS-like 'correct' usage with 'professionalism.' Their BELF use was characterized by local, 'company speak', translingual practices and the accommodation of both non-native (NNS) and native (NS) speakers of English, and the ways in which the latter were accommodated displayed a more positive attitude to these interlocutors than has been found in similar studies. This article argues that English used as a corporate language is a complex phenomenon requiring business professionals to have a wide set of communication resources and the ability to use the language flexibly.
\end{abstract}

\section{Keywords}

ELF; BELF; communication accommodation; corporate language; business discourse; communication in international business

\section{Introduction}

The main international business language today is English (Charles 2007, Gerritsen/Nickerson 2009). Moreover, the context in which English is currently used in business is characterized by people interacting across borders frequently, many of them being part of the complex and far-reaching networks of Multinational Corporations (MNCs), which may choose English as their official corporate language. This choice is intended to make communication more efficient, less costly, and allow for better control from HQ (Charles/Marschan-Piekkari 2002, Piekkari et al. 2014). However, studies on the characteristics of English when used as a shared language resource (Lingua Franca) in a globalized world indicate that this communication requires more than good English language skills based on native speaker standards. Indeed, research on English as a Lingua Franca (ELF) (Jenkins et al. 2011), and English as a Business Lingua Franca (BELF) (LouhialaSalminen et al. 2005, Kankaanranta/Louhiala-Salminen 2013), demonstrate the need for flexible communication strategies to adjust to many different contexts, situations, people, languages and cultures (Kankaanranta et al. 2015). The actual language use is also so fluid that meaning must be negotiated locally (Kankaanranta et al. 2015), and Blommaert (2010) suggests that in our globalized world, languages can be considered mobile resources that are used differently depending on the context. As for the MNC context, these organizations are themselves inherently multilingual and multicultural sites that are constantly influenced and shaped by the emergent communication

\footnotetext{
* Tone Holt Nielsen Department of Teacher Education and School Research, University of Oslo Oslo Business School, Oslo Metropolitan University

E-mail: toneni@oslomet.no
} 
practices of their employees (Karhunen et al. 2018). Thus, what 'English as a corporate language' might mean in terms of how business professionals in MNCs use it, is a complex question, and therefore the need to understand when and how they communicate in English in specific MNC contexts has become ever more pressing. Such information can inform MNC management about some of the implications of choosing English as their corporate language.

English dominates as the official corporate language in MNCs in all the Nordic countries (Harzing/ Pudelko 2013), and the English proficiency levels in the region are consistently described as "very high" (https://www.ef.no/epi/). In Norway, studies of language needs in business contexts have all found a widespread and growing use of English (Hellekjær 2012, Hellum/Dypedahl 1998, Lie/Skjoldmo 1982). Yet, at the same time, Hellekjær (2012) reported that a number of his respondents experienced difficulties using English in demanding situations like negotiations and presentations. Thus, English is clearly important for business professionals in Norway, yet, while general English proficiency may be good, there are still problems when communication in complex business contexts is called for. The studies above were all quantitative surveys, which did not aim to provide details about how these professionals use the language. To fill this gap, the present study employs semi-structured interviews with a number of MNC staff to understand more about which tasks they need to carry out in English, as well as characteristics of their use of English as a Business Lingua Franca (BELF). To my knowledge there have been no other qualitative studies in Norway on English use in MNCs. Hopefully, the rich data such a study can provide will contribute to our understanding of what characterizes BELF use, and in turn inform both educational institutions and businesses about what is actually needed.

Thus, the questions that the present study will address are the following:

1. What are the BELF communicative needs of business professionals in MNCs in Norway?

2. What characterizes BELF use in MNCs in Norway?

\section{Literature Review}

In addition to the studies relating to the Norwegian context, this article will draw on literature from the fields of English Lingua Franca (ELF), English as a Business Lingua Franca (BELF) and International Business (IB). Relevant literature and theory are presented and discussed below.

\subsection{English lingua franca and English as a Business Lingua Franca}

A number of researchers have aimed to understand what characterizes English when it is used as a Lingua Franca (ELF) (Jenkins et al. 2011), that is, "a contact language between speakers or speaker groups when at least one of them uses it as a second language" (Mauranen 2018: 8). Substantial research has also been done on ELF in the business context, English as a Business Lingua Franca (BELF) (e.g. Cogo 2016, Ehrenreich 2010, Kankaanranta/Louhiala-Salminen 2010a, Kankaanranta/Planken 2010b, Louhiala-Salminen et al. 2005). Kankaanranta/Louhiala-Salminen note that what makes BELF as a communication resource distinct is "its domain of use (international business), the role of its users (professionals), and the overall goal of the interactions (getting the job done)" (2018a: 309).

Early attempts at codifying (B)ELF as a stable 'variety' of English have been abandoned, since the actual discourse was found to be so varied as to resist codification, and recent research states that (B)ELF discourse is particularly fluid and flexible, changes continually depending on the situation, and is locally enacted and negotiated (e.g. Kassis Henderson/Louhiala-Salminen 2011, Kankaanranta et al. 2015, Kankaanranta et al. 2018b). According to Komori-Glatz the current phase of ELF research focuses on the specifics of interaction in particular contexts, and she defines BELF as "a flexible, variable and hybrid resource that is highly context-bound and which both 6 constitutes and is constituted by the community using it" (2018: 56). Thus BELF does not 
exist a priori, as a 'version' of English, but emerges through use, as a social practice where people use a number of communicative resources, English linguistic proficiency being only one of them, as they adapt to different people and contexts (Kankaanranta et al. 2018b). Hence, 'English use' will be conceptualized in this study as a social practice that involves several communication strategies and resources.

Research findings on the characteristics of ELF and BELF use overlap to a great degree, but the distinctive domain and context of business make BELF use different in significant ways. (B) ELF discourse tends to have a content, not linguistic or grammatical, focus, and clarity has been deemed essential (Cogo 2009, Jenkins et al. 2011). The issue of clarity is particularly pertinent for BELF since getting the job done is paramount in business interactions (Ehrenreich 2010, Kankaanranta/Louhiala-Salminen 2010a). Additionally, in business, there is a need for highly contextualized knowledge of domain-specific vocabulary (e.g. Kankaanranta/Planken 2010b). BELF has also been found to be an issue in specific communicative situations or genres like negotiations (Planken 2005) or business meetings (Rogerson-Revell 2007, 2008, 2010).

(B)ELF discourse requires speakers to adjust to a wide array of interlocutors since it involves both native speakers (NS) and non-native speakers (NNS) of English (Cogo 2016, Mauranen 2018), as well as other languages and cultures (Kassis Henderson 2005, Meierkord 2002). Accordingly, an important factor for successful (B)ELF communication has been found to be the ability to use a number of 'accommodation strategies' (Giles/Coupland 1991) to adjust to others in terms of both language and culture (Cogo 2009, 2016, Jenkins et al. 2011, Kankaanranta/Planken 2010b, Rogerson-Revell 2010). Giles/Coupland (1991: 62-74) developed a communication accommodation theory for understanding the ways in which speakers accommodate each other. While 'convergence strategies' are ways in which people adjust their communication towards that of others, for example for reasons of social approval, instrumental goals or increased intelligibility, they may also choose 'divergence strategies' to accentuate differences to maintain identity or signal distance. Typical convergence strategies can be to use a simple vocabulary, speak more slowly, repetition and clarification checks. Furthermore, culture and other languages may influence BELF interaction (e.g. Kassis Henderson 2005, Kassis Henderson/Louhiala-Salminen 2011, Louhiala-Salminen et al. 2005). Since (B)ELF is used in multilingual contexts, knowing and using several languages has been found to be an advantage to build trust (Cogo 2016, Kassis Henderson/Louhiala-Salminen 2011), and to accommodate through 'translanguaging' (García/Wei 2014), when a person mixes words from different language resources to meet the specific communication needs of a situation (Cogo 2012). Indeed, Canagarajah (2018) points out that it is clear that synergies are created when several language resources are used together with English, and that we cannot analyze these as separate entities. As far as culture is concerned here, this concerns mainly how people of diverse sociocultural backgrounds may show different preferences for language use (Spencer-Oatey/Jiang 2003). Kassis Henderson/Louhiala-Salminen (2011) stress that intercultural accommodation is crucial for BELF, and Kassis Henderson (2005) suggests that business professionals negotiate new, shared linguacultural conventions, for example regarding politeness.

Whether interlocutors are NNS or NS often seems to play a role and influence the communication practices in various ways. NNS have been found to see other NNS as 'equals', while NS could make NNS feel intimidated or inferior, or perceive that NS used their linguistic advantage as a tool for power (Cogo 2016, Ehrenreich 2010, Kassis Henderson/Louhiala-Salminen 2011, Kankaanranta/Planken 2010b). Moreover, NS were often found to be less adept at accommodating to various speakers than NNS, and to speak too fast or use a too advanced language (Charles/ Marschan-Piekkari 2002, Cogo 2016, Kankaanranta/Planken 2010b, Sweeney/Hua 2010). Thus, the linguistic skills of NS do not automatically make them good communicators in (B)ELF interactions that require more complex communicative strategies (Karhunen et al. 2018). 


\subsection{English as a corporate language}

This article will also draw on some studies from the field of International Business (IB) that address the question of language in MNCs. One caveat, however, is that many studies in IB typically do not focus on "how 'English' is conceptualized, how it is used, or what the discourse is like" (Kankaanranta et al. 2015: 134). The latter is important in BELF and the present study, where language is conceptualized as a social practice, whereas in some IB studies it is often regarded as either a context-independent 'system' that management can implement, or as a question of individual competence (Karhunen et al. 2018).

Research findings in IB show various consequences of the introduction of an official corporate language that can shed a light on the findings here. For instance, studies have uncovered that an individual's communication skills in the corporate language can become a power factor; empowering those with good skills, giving them more influence, access to better information, jobs and training; while disempowering those with more limited skills (Bjørge/Whittaker 2015, Piekkari et al. 2014, Welch et al. 2005). Neeley's study (2013) showed that those who perceive their own levels of English as inadequate may experience status loss, and some researchers also stress that there is reason to question to what extent the corporate language really is a 'shared' idiom (Fredriksson et al. 2006). Related to this, several studies in IB have discussed how employees at international companies may develop their own, local 'company speak' comprising features like shared jargon and communicative norms that evolve over time (Welch et al. 2005), together with a mix of English terms and local words and expressions (Logemann/Piekkari 2015). Aichhorn/ Puck, who studied English used as a corporate language in two Austrian MNCs, claimed that company speak could create "a shared cognitive ground that facilitates sense-making" (2017: 398), and function as a shorthand version of the corporate language.

\section{Methods}

The present study follows up on results from Hellekjær (2012), who reported on the use of foreign languages, especially English, in Norwegian export businesses. Whereas he used a quantitative survey approach, the present study is a qualitative multi-site thematic case study (Bishop 2010) employing interviews with business professionals about their need for and use of BELF at work.

Extant literature on BELF use has shown that business practitioners tend to focus on the purpose and goal of their communication, 'getting the job done' (e.g. Kankaanranta/Planken 2010b, Ehrenreich 2010). Moreover, Canagarajah suggested that in ELF research, the activity should be the unit of analysis since "Meaning-making is in the service of whatever activity is being accomplished by the participants - i.e. working" (2018: 812). Accordingly, Michael Long stated that while domain experts are excellent sources of information about professional language use, they "can provide valid information about the work they do in terms of tasks, but not in terms of language" (2005: 23). Thus, the unit of analysis for the present study refers to the tasks carried out at work using BELF.

The interviews were semi-structured, and attempted to "understand themes of the lived everyday world from the subjects' own perspectives" (Kvale/Brinkmann 2009: 27). An interview guide with questions loosely structured around main points was used, and this guide was piloted and adjusted. For instance, the word 'accommodation' confused the interviewee, so in subsequent interviews the more general term 'adjusted' was used. However, the subjects were allowed to speak freely about their experiences using their own words, with only minimal probing from the researcher. First, there were background questions about the interviewees' education and positions, as well as the role of English in the company. Second, they were asked about the tasks they carried out in English, characteristics of the communication, with whom they communicated, and

how well they thought they managed using English at work. However, the answers regarding their self-assessment of English use are not reported here, since communicative competence is not addressed in this article. 
The interviews were approximately 40-60 minutes long and were conducted, recorded and then transcribed in full in Norwegian. Excerpts and quotes used in the present article were translated by the author. Thematic coding of the interviews was done in two rounds. The first cycle ascribed vague descriptive labels, while in the second round early patterns were collected into larger thematic categories linked to the research questions of the study. The data was analyzed in the software program for qualitative data analysis, Nvivo.

Recruitment of the interviewee sample involved three approaches, advertising through a professional organization for business professionals, formal contacts with key personnel in the organizations, and using personal contacts of colleagues and interviewees. The two latter methods were the most successful. The interviews were carried out between March and June 2015 with nine respondents, four men and five women, from six different MNCs in the oil and gas as well as the telecom/IT sectors. These MNCs either were or had subsidiaries and partners in other countries; some had owners and/or top management abroad; and most had outsourced some service functions like IT and accounting. All of the MNCs had English as their official corporate language and the interviewees used it daily. While the interviewees all worked in divisions or headquarters of their MNCs situated in Norway, an MNC is "a networked organization embedded in different national environments" (Marschan-Piekkari et al 2004: 251), and its knowledge and communication flows will be both local and global at the same time.

All the interviewees had a degree in Economics and Business Administration, and were all in their 30s and 40s. They held typical positions for business professionals in these kinds of organizations, although a majority were in top- or mid-level management positions (see table 1). To get access to MNCs can be a challenge, both access to the business itself, and, secondly, access to informants. Most of those I reached might be regarded as part of an elite set of people in the higher echelons of MNCs, which could arguably be a group whose experiences may resemble each other's more across borders than across hierarchies within a national division (Marschan-Piekkari et al. 2004). The identities of both the interviewees and the organizations participating in this study are protected for ethical reasons.

\begin{tabular}{|c|c|c|}
\hline Pseudonym & Job title & Typical tasks carried out in English \\
\hline $\begin{array}{l}\text { 'Morten', } 38 \\
\text { MNC 1 }\end{array}$ & Auditor & E-mails, reports, phone calls, meetings \\
\hline $\begin{array}{l}\text { 'Caroline', } 40 \\
\text { MNC } 1\end{array}$ & $\begin{array}{l}\text { Head of Finance } \\
\text { and Controlling/ } \\
\text { (CFO) }\end{array}$ & E-mails, presentations, reports, meetings \\
\hline $\begin{array}{l}\text { 'Miriam', } 48 \\
\text { MNC } 2\end{array}$ & $\begin{array}{l}\text { Head of Accounting } \\
\text { and Controlling of } \\
\text { one division of this } \\
\text { MNC }\end{array}$ & E-mails, presentations, reports, phone calls, meetings, chat function, contracts \\
\hline $\begin{array}{l}\text { 'Carl', } 46 \\
\text { MNC } 3 \\
\end{array}$ & $\begin{array}{l}\text { Chief Financial } \\
\text { Officer (CFO) }\end{array}$ & E-mails, presentations, reports, phone calls, meetings, contracts \\
\hline $\begin{array}{l}\text { ‘Helene', } 36 \\
\text { MNC 4 }\end{array}$ & Lead Controller & E-mails, reports, phone calls, meetings \\
\hline $\begin{array}{l}\text { 'Hanne', } 48 \\
\text { MNC } 5\end{array}$ & $\begin{array}{l}\text { Manager Control } \\
\text { and Finance, HR }\end{array}$ & E-mails and presentations \\
\hline $\begin{array}{l}\text { 'Fredrik', } 39 \\
\text { MNC 5 }\end{array}$ & Senior Analyst & E-mails, presentations, phone calls, meetings, chat function, documents \\
\hline $\begin{array}{l}\text { 'Jan', } 35 \\
\text { MNC } 5 \\
\end{array}$ & Lead Controller & E-mails, presentations, phone calls, meetings, chat function, documents \\
\hline $\begin{array}{l}\text { 'Anne', } 35 \\
\text { MNC } 6\end{array}$ & $\begin{array}{l}\text { Lead Sales } \\
\text { Controller/ Bid } \\
\text { Manager }\end{array}$ & E-mails, presentations, reports, phone calls, meetings, chat function, letters \\
\hline
\end{tabular}

Table 1: About the sample. The table details the interviewees' pseudonyms, ages, job titles and which tasks they carried out using English

The article thus reports on the individual experiences of nine Norwegian business professionals working in six different MNCs, which limits any claims respecting generalizability. However, BELF use is always emergent and varies across contexts (Kankaanranta et al. 2018b), and there- 
fore theory development in this field will be in constant flux. Further, Eisenhardt/Graebner (2007) claim that multiple case studies are excellent for further development of emergent theories, as knowledge can be found inductively, and patterns may appear across cases. Moreover, Kankaanranta/Louhiala-Salminen suggest that part of the ' $B$ ' in BELF signifies shared international practices in business, that is, what is appropriate and when: "business practitioners seem to share knowledge of the patterns on what, why, how, and when to communicate in a particular situation" (2018a: 318).

\section{4. $\quad$ Findings}

The findings will be presented under the headings of the two research questions. The first part addresses RQ1: What are the BELF communicative needs of business professionals in MNCs in Norway? This comprises findings on how the organization and the interviewees defined the need for English, and which tasks the interviewees needed to carry out in English at work. The second part presents findings relevant for RQ2: What characterizes BELF use in MNCs in Norway? Findings here detail characteristics of the language use like 'company speak' and communication strategies used with NS and NNS interlocutors respectively.

\subsection{What are the BELF communicative needs of business professionals in MNCs in Norway?}

First, the interview questions regarding this topic addressed the official English requirements of the MNCs, as well as what the interviewees themselves thought was required. Second, they were asked which tasks they needed to carry out in English, how often, and what they thought were the least and most demanding to do.

English was the official corporate language of all six MNCs in this study, and everyone said their organizations required that you were be able to use it at work, "it is one of the basic skills that it is expected that you master" (Jan). However, when hiring, the candidate's English communication abilities were sometimes, but not always, addressed. Thus, this seems to confirm the view put forth by Graddol (2006), that English has come to be regarded as a 'basic skill' that you are expected to have, and therefore it might not be specifically mentioned in recruitment processes (Ehrenreich 2010).

Needs for English as defined by the interviewees, focused on knowing professional business terminology, accomplishing the purpose of their communication, and would vary with your position. There was a consensus that a clear message, "what is the bottom line?" (Caroline), that to understand and be understood correctly were the most important: "to be able to communicate, to express what we want done, to do our job" (Helene). In addition, while everyone would need to do some tasks in English, some positions required the ability to use it in more complex situations. For instance, manager informants stressed that your career opportunities would be limited if you did not communicate well in English, since the higher the position, the more you would need to use it in advanced and complex settings:

\footnotetext{
If you are in my type of role or similar, where you have to give presentations in English (...), you think to yourself that you lack the words, and will fumble, and "uhm", "eh", if your mind goes blank at times then, it will be the same, you may come across as a complete idiot, while you are actually a really good leader who is in full control of everything. (Caroline)
}

Some even felt weak skills could lead to a loss of face:

There have been like, well, the English has been bad, which makes others who have been present embarrassed, then also, the other party reacts. (Miriam)

English use was widespread and increasing in these organizations, and its use was either mandated or a pragmatic choice (see table 1 for which tasks each of the nine interviewees do in English). All these businesses expected that official reporting to, and communication with, top management 
should be in English, and some documents, like contracts, had to be. As for pragmatism, several informants noted that writing in English in e-mails and presentation slides in the first place was seen as being more efficient; "because sometimes the information is passed on, and then it might be someone who is an English speaker who receives it later, so we use it all the time" (Fredrik). Moreover, day-to-day communication in English with colleagues or outsourced service personnel would occur at many levels of the organizations, and it would be used if it was the only shared language.

The interviewees were asked about the written tasks and situations for which they needed English. All of them wrote e-mails and reports in English and several also wrote in a chat program, documents for meetings, formal letters and contracts. Of these, writing E-mails was the most frequent task, followed by chats. They thought that writing e-mails was something they mastered quite well, although they spent more time on them than in Norwegian, and several said they might lack the English vocabulary to express all the nuances they would like to. For instance, 'Jan' said that his language became stiffer and less fluent, and that he had perhaps come across as less polite because he did not know how to make the language less direct, or to hedge what he was saying:

\footnotetext{
Then, when I am being misinterpreted, I can often get an emotional answer back, where I had no intention of offending, but had a message without...yes, it was not sent, it was not sent with an exclamation mark, but it was read as if there was an exclamation mark. (Jan)
}

Last, several thought that there was some leeway in oral communication as far as using grammatically correct language was concerned, while written English ought to be 'correct'. One manager reported she had received documents where subordinates had used Google translate: "Which is completely hopeless" (Caroline), and another added:

\footnotetext{
And the worst we see that is really many written mistakes, or, poor written English. That is very damaging. It is a source of irritation; it seems as if it has not been thoroughly prepared. (Jan)
}

As far as spoken interaction was concerned, presentations were the most frequent, followed by phone calls, small talk and meetings. The two latter were deemed the most demanding activities, especially meetings, where they felt they had to concentrate harder, and, importantly, several noted such negative effects as feeling overwhelmed and tired, and that it could be hard to take part in a complex discussion:

\footnotetext{
In a discussion you have to improvise, and, you have to, in addition to formulating your arguments, which can be tough too, then you have to translate them into English, and your whole argument may be seriously weakened if you cannot also find the right language to use. (...) you can miss the opportunity to participate in the discussion. And then, 'Oh", then the discussion has moved on before your argument is ready, and you can be 'disconnected' [from the conversation]. (Carl)

If you are sitting in a meeting, and say that there is a heated discussion about something that you would really like to say something (...) but if you are uncertain of the language, then you do not want to interrupt and go for it in the same way. (Caroline)
}

To sum up, the findings on BELF communicative needs show that English is widely used and needed in these MNCs. The informants stressed getting the job done, that they needed specific business terminology, and displayed a pragmatic attitude to when they would use BELF. These findings are very much in line with other BELF studies (e.g. Kankaanranta/Louhiala-Salminen 2010a, Kankaanranta/Planken 2010b, Ehrenreich 2010). Still, while job accomplishment was seen as the most important, some of the informants seemed concerned with the bad impression less 'correct' and fluent language use could cause, perhaps to a somewhat greater degree than in similar studies (e.g. Kankaanranta/Planken 2010b, Ehrenreich 2010). Thus, while Kankaanranta et al. (2018b) stress that not all positions would need linguistic competence that requires NSlike 'correct' usage, this was not fully supported by the interviewees here who seemed to associate being 'professional' with 'correct' usage. Last, while the interviewees typically said that they found it quite easy to handle everyday, concrete tasks, meetings were found difficult to handle, ta- 
king part in discussions in particular, which is similar to findings in other studies (Hellekjær 2012, Neeley 2013, Rogerson-Revell 2007). Thus, meetings are professional situations in which using BELF may limit both the efficiency of the company and the influence of NNS.

\subsection{What characterizes BELF use in MNCs in Norway?}

Questions on this topic regarded various aspects of BELF use in their organizations, such as local, specialized language use, the use of other language resources, as well as how they accommodated various interlocutors. For the latter, the informants distinguished clearly between communicating with and adjusting to NS and NNS interlocutors.

The nature of the language they used internally was described as a highly specialized, local 'company speak', or 'tribal language', with terms in English that were specific not just to their sector or field of expertise, but to their organization. Some of the MNCs even had internal webpages explaining the meaning of these terms, and 'Carl' mused that "we have terms for things that may be unique (...) the corresponding terms at a competitor would perhaps be a bit different", and 'Jan' said you had to learn the 'company speak' through experience and co-operation with colleagues.

English use in these multilingual companies was also characterized by translingual practices, where it was mixed with Norwegian and other languages. For instance, many of the interviewees admitted using English professional terms even when they spoke in Norwegian as they did not always know the corresponding Norwegian terms. Frequently, they used written presentation slides in English, while presenting in Norwegian, which could be confusing:

The language will not be very good when you have a presentation in English and you present in Norwegian (...) you glance at it, and you see the English, then, well... (Miriam)

Another translingual practice mentioned was related to the negotiation of meaning in BELF, when people used other language resources in their repertoire. For example, a Dutch word might be understood by a Norwegian since the languages have some similarities, and Swedes and Norwegians would use a mixture of their respective native languages with each other (Helene).

Communicating with NS was seen as easy by some, "they adjust and slow down, and they know that they are speaking to someone who is not a native speaker" (Jan), while most found it challenging. Several struggled with the wider vocabulary NS used and the speed at which they were speaking, and that they tended to be less prepared to deal with the wrong usage of words; "the Americans take it literally" (Helene). Moreover, a few claimed that speaking with NS made them feel "stupid" or "inferior" (Helene) and:

Some feel, right, not very good, and do not find the right expressions, and feel that, oh, now you are sitting there and just, with a red marker afterwards, sort of (...) Yes, it is the experience of it, that you feel, I would almost say inferior, since you feel insecure. (Miriam)

Additionally, one informant felt overwhelmed by NS using many words, and mentioned that her and others' hesitation to discuss with them might lead to them ceding power: "you just say 'yes', then we do it like that, and then we do not discuss much, because it is so..." (Anne). However, several also said that they adjusted to NS by trying to perform better:

To communicate with for instance the English or Americans, then you have to, what should I say, "man up"! Perform particularly well. (Caroline)

You try to speak as correctly as possible and, with grammar and those little words and such. (Anne)

In general, the informants regarded NNS as equals when using English, and they used a number of different accommodation strategies to adjust to these interlocutors. Communication with other NNS, was seen as more relaxed than with NS, although there were some challenges too:

There is, what should I call it, more room for stammering and searching for words. (Carl) 
When I communicate with equals, who are also non-native speakers, there can often be miscommunication, misunderstandings (...) the accents of Asian speakers are harder for me to understand. (Jan)

In order to adjust to NNS, several said they simplified their language to achieve clarity:

You must not confuse somebody who does not speak English as a native language by using lots of grand words and expressions and, I think it is very important to write short, simple e-mails. (Caroline)

You simplify a bit, how should I say it, that is, when you speak to a Chinese person you try to be, somehow, a bit more precise really. (Anne)

Interestingly, 'Carl' estimated that his English use varied greatly depending on whether the interlocutor was NS or NNS:

I speak an English which is much worse with non-native speakers than with native speakers, speak with a much better accent actually, and I feel that I have a better vocabulary, too, when speaking with the British. (Carl)

Most of the interviewees thought that culture played a role in how English was used and perceived, and they adjusted to linguacultural differences. They had noted different attitudes to time, hierarchy, levels of formality and the role of relationships in business, which would be manifest in different linguacultural practices. First, several interviewees thought that many cultures tended to be more formal in terms of verbal politeness than Norwegians:

Actually it is my impression that everyone is more polite than in Norway (laughing)! (Fredrik)

We tend to not use any politeness words even if there are people high up in the system [that you address]. (Hanne)

Some thought that verbal politeness might be connected to the language, English, itself, a culture in the language, "I think that English is a more polite language than Norwegian" (Helene). Second, they stressed that it would vary how direct you can be: "In Asia, they are so polite (...) there are so many phrases! (...) and we are just, "the report, here it is"' (Miriam). Hence, some might adjust their writing style:

There are some that elaborate a lot, like, yes, a bit like in the Middle East, it is a bit like that there, yes, they use a lot of polite phrases before they ask about anything. (...) I must make sure that I write a bit like that myself, too, so that you do not seem impolite. (Fredrik)

Last, some of them mentioned that there is a preference for more relational talk in many countries, while commenting on hierarchies which could be seen as a hindrance from a Norwegian point of view:

I do some small talk and am a bit disarming before we start with the subject. Ask about family and children and hobbies, and, those things, so I hope through that that it can take down, or take away some of the hierarchy, which is a hindrance. (Jan)

Thus, BELF use in these six MNCs was characterized by a local 'company speak', translingual practices, as well as the use of a wide array of accommodation strategies to adjust to both NS and NNS, both in terms of language and culture.

\section{Discussion}

Many of the characteristics of English needs and use in this study align with other studies of BELF discourse. It shows that communication is likely to be highly dynamic and changing from situation to situation (e.g. Kassis Henderson/Louhiala-Salminen 2011, Kankaanranta/Planken 2010b), in addition to the strong focus on the use of English enabling the interviewees to do their jobs being more important than the code itself (Ehrenreich 2010, Kankaanranta/Louhiala-Salminen 2010a, Kankaanranta/Planken 2010b, Louhiala-Salminen/Kankaanranta 2012). However, two findings merit a closer look: One concerns the nature of 'company speak', the other relates 
to the various accommodation strategies employed with NS and NNS respectively. These will be discussed below.

An interesting finding in the present study is the notion of 'company speak' or 'tribal language', where professional and company-specific terms were used in a highly context-dependent way. Moreover, sometimes this was a translingual practice (García/Wei 2014), where Norwegian was mixed with domain-specific English terms. 'Jan' said that the company speak was developed through interaction with colleagues, which confirms Welch et al.'s (2005) suggestion that these are shared communicative norms that develop over time. Aichhorn/Puck (2017) stated that company speak was a result of accommodation processes internally, leading to a shared 'shorthand' of the corporate language, which Logemann/Piekkari (2015) claimed was created bottom-up by the users. Thus, the company speak could be considered an aspect of the corporate language that is truly shared, unlike the official NS-based version mandated from the top (Fredriksson et al. 2006). Indeed, some researchers claim that company speak can create a "sense of belongingness" (Logemann/Piekkari 2015: 47), and contribute to a unique company culture (Aichhorn/Puck 2017).

Accommodation strategies that can aid people when negotiating meaning locally seems to be a salient feature of (B)ELF communication, and were also found to be important in the present study (Cogo 2016, Charles/Marschan-Piekkari 2002, Jenkins et al. 2011, Kankaanranta/LouhialaSalminen 2013, Louhiala-Salminen et al. 2005). However, present findings revealed that communicating with NS or NNS respectively raised different challenges, and the informants chose different accommodation strategies according to this distinction.

Communicating with NS was perceived to be challenging in both cognitive and affective ways. First, NS' who spoke fast and used an advanced vocabulary were found to be problematic, which has been widely reported elsewhere (e.g. Cogo 2016, Ehrenreich 2010, Kassis Henderson/Louhiala-Salminen 2011, Louhiala-Salminen/Kankaanranta 2012, Sweeney/Hua 2010). Second, most thought NS were less flexible and willing to accommodate them than NNS (Ehrenreich 2010, Sweeney/Hua 2010), and then, in fact less competent communicators in these situations. Next, some informants felt insecure when speaking with NS, and reported that they became passive and dropped important issues, effectively limiting their own influence (Neeley 2013, Charles 2007). Indeed, NNS feeling that they are ceding power to NS, or their taking advantage of their native skills, have been found in several studies (e.g. Ehrenreich 2010, Hellekjær/Fairway 2015 in the public sector in Norway). Thus, cognitive difficulties could either be eased by NS learning to accommodate better (Charles/Marschan-Piekkari 2002), or by NNS improving their skills. Affective reactions to dealing with NS may be harder to address, but awareness on the part of NS would clearly be helpful, as would NNS addressing their lack of confidence as speakers.

However, several of the interviewees in this study had a more positive attitude to interaction with NS. Some, like 'Jan', thought that NS were good at accommodating him, for instance by slowing down. Additionally, several attempted to converge to their NS interlocutors by trying to perform better, be more correct in their language use, as well as develop a more advanced vocabulary. 'Carl' even claimed that he emulated the language of NS when interacting with them, and that his language became much better then. This more positive view of NS interlocutors and NSlike language use contrasts with a tendency in much BELF literature to focus on the problems of NS' participation in BELF interactions, such as those mentioned above, as well as stating that NS-like language use is not a model. For instance, the German managers in Ehrenreich's study thought being grammatically correct was "irrelevant" for all but important written texts (2010: 417-418), and Kankaanranta/Planken (2010b) found that while their Finnish and Dutch informants wanted to keep up with NS, they did not see NS-like linguistic competence as a model to strive for. Why then, did the Norwegian informants want to emulate NS? Norwegians are arguably highly proficient speakers of English, and Norwegian, a minor language spoken by only 5.2 million speakers, was deemed less polite, and as having fewer words and nuances than English. In addition, these particular informants may have had more contact with NS than others, or belong to a management 'elite' of international business professionals (Marschan-Piekkari et al. 2004). 
Yet, the findings on this topic were fairly consistent across several of the MNCs, suggesting that this wish to emulate NS might be a tendency for Norwegian speakers of English, and represents a more active stance than merely resenting or avoiding NS.

Using English as a lingua franca among NNS was perceived as 'neutral', and more relaxed than with NS (Kankaanranta/Planken 2010b, Piekkari et al.2005). The interviewees accommodated NNS by using a number of convergence strategies like simplifying their language and speaking more slowly, as well as trying to be as precise as possible in their choice of words. A particularly interesting finding is what 'Carl' said about his English use converging to that of his interlocutors, with his English being "much worse" when speaking with NNS. While he did not seem to think he did this deliberately, this may be an example of divergence from the NS accents, since these may represent power and distance, while stressing his Norwegian identity and status as a fellow NNS (Giles/Coupland 1991). Thus, by aligning himself with other NNS, he can take advantage of the perceived 'neutrality' of BELF in NNS-NNS interactions and gain the social approval of other NNS (Cogo 2016). Since 'Carl', as mentioned above, is also capable of converging with NS English use, he is a good example of somebody who can use a wide set of communication resources to great advantage in BELF interactions.

The interviewees also accommodated NNS through the use of translingual practices and adapting to linguacultural differences. Interaction with other NNS could involve the use of several languages to achieve joint meaning-making. This suggests that having a repertoire of several languages is an advantage for (B)ELF communicators (Cogo 2012, 2016, Ehrenreich 2010, Harzing/Pudelko 2013, Louhiala-Salminen/Kankaanranta 2012, Meierkord 2002). Furthermore, the interviewees' comments on linguacultural differences showed that they clearly perceived the importance of accommodating these, and they focused on politeness norms in particular. Hence, the adjustments they made to accommodate others seemed to be motivated by a wish to preserve good rapport, rather than simply be understood. For example, 'Fredrik' adopting a more elaborate writing style when corresponding with someone from the Middle East might be an example of a new, negotiated linguacultural practice (Kassis Henderson 2005).

To conclude, while this study comprises only six MNCs and nine informants, which limits any claims to generalizability, the findings were both very similar across these sites and to BELF studies from other countries. Moreover, the interview method allowed for tacit knowledge about complex work processes to be discussed and brought to light. Thus, while the use of BELF as a communication resource is very diverse, there were also clear patterns to the needs and uses across these cases, and the study contributes further empirical data to the emergent theories on (B)ELF.

\section{Conclusion}

The results of a qualitative study such as the present can provide useful details on the complex nature of a corporate language in terms of how business professionals use it to carry out various tasks at work. Based on the findings here, BELF as a complex communication resource is an important component of corporate language, but so are the local 'company speak' and sometimes a more formal, NS-based English. Kankaanranta et al. (2018b) claim that 'English as corporate language' can indeed encompass both NS-like linguistic proficiency and the more fluid BELF resource, however, they indicated that for most employees the latter would suffice. While this might be true to a certain extent, extensive English use was in the present study seen to permeate all levels of the MNCs, and advanced skills in the corporate language still appeared to have some gatekeeping function (Piekkari et al. 2014). Moreover, whereas this study confirmed that getting the job done is at the forefront of BELF communication, it is important to acknowledge the sometimes negative affective experiences of using English as a Business lingua franca felt by NNS (Neeley 2013), as well as the need to accommodate linguacultural differences to improve rapport. Last, going forward it would perhaps be fruitful to have less focus on NS as a problem, and like the in- 
terviewees in the present study, display a more positive and constructive attitude towards these interlocutors in BELF interaction.

Whereas there has been a growth in research on (B)ELF interaction in later years, as well as a greater focus on the linguistic factor in business, there is still a dearth of studies and much ground to cover (Nickerson 2015, Tenzer et al. 2017). The questions addressed here need to be pursued further; for instance a close study of context-specific BELF discourse, especially of demanding tasks like meetings, could give even more depth of knowledge on this important topic. In the Nordic region, focusing on the language use of business professionals with supposedly 'very high' English proficiency could be a potential avenue of research. Other studies could also take a more pedagogic angle to understand the nature of communicative competence in this context, which could change how English is taught at various levels, especially in higher education and in-service training. This study shows the need to gather more data about the use of English as a Business Lingua Franca, because it is such a complex phenomenon that is continually in flux and as mobile as its users.

\section{References}

Aichhorn, Nathalie/Puck, Jonas 2017: Bridging the language gap in multinational companies: Language strategies and the notion of company-speak. In Journal of World Business 52, 386-403.

Bishop, Pam 2010: Multi-Site Case Study. In Mills, Albert. J./Durepos, Gabrielle/Wiebe, Elden (eds.), Encyclopedia of Case Study Research. Thousand Oaks: SAGE Publications Inc., 588-590.

Bjørge, Anne Kari/Whittaker, Sunniva 2015: Language Management in a Multinational Workforce: The Knowledge Worker Perspective. In Hermes - Journal of Language and Communication in Business 54, 137-160.

Blommaert, Jan 2010: The Sociolinguistics of Globalization. Cambridge: Cambridge University Press.

Canagarajah, Suresh 2018: The unit and focus of analysis in lingua franca English interactions: In search of a method. In International Journal of Bilingual Education and Bilingualism 21(7), 805-824.

Charles, Mirjaliisa 2007: Language Matters in Global Communication: Article Based on ORA Lecture October 2006. In Journal of Business Communication 44, 260-282.

Charles, Mirjaliisa/Marschan-Piekkari, Rebecca 2002: Language Training for Enhanced Horizontal Communication: Challenge for MNCs. In Business Communication Quarterly 65(2), 9-29.

Cogo, Alessia 2016: "They all Take the Risk and Make the Effort": Intercultural Accommodation and Multilingualism in a BELF Community of Practice. In Lopriore, Lucilla/ Grazzi, Enrico (eds.), Intercultural Communication: New Perspectives from ELF. Roma: Roma TrE-Press, 365-383.

Cogo, Alessia 2012: ELF and super-diversity: A case study of ELF multilingual practices from a business context. In Journal of English as a Lingua Franca 1-2, 287-313.

Cogo, Alessia 2009: Accommodating Difference in ELF Conversations: A Study of Pragmatic Strategies. In Mauranen, Anna/ Ranta, Elina (eds.), English as a Lingua Franca: Studies and Findings. Newcastle: Cambridge Scholars Publishing, 254-273.

EF Epi - English Proficiency Index [online]. https://www.ef.no/epi/ (Accessed 19 February 2018).

Ehrenreich, Susanne 2010: English as a Business Lingua Franca in a German Multinational Corporation. In Journal of Business Communication 47, 408-431.

Eisenhardt, Kathleen/Graebner, Melissa 2007: Theory Building from Cases: Opportunities and Challenges. In The Academy of Management Journal 50(1), 25-32.

Fredriksson, Riika/Barner-Rasmussen, Wilhelm/Piekkari, Rebecca 2006: The Multinational Corporation as a Multilingual Organization: The notion of a common corporate language. In Corporate Communications: An International Journal 11 (4), 406-423.

García, Ofelia/Wei, Li 2014: Translanguaging: Language, Bilingualism and Education. Basingstoke: Palgrave Macmillan.

Gerritsen, Marinel/ Nickerson, Cathrine 2009: BELF: Business English as a Lingua Franca. In Bargiela-Chiappini, Francesca (ed.), The Handbook of Business Discourse. Edinburgh: Edinburgh University Press, 180-192.

Giles, Howard/Coupland, Nikolas 1991: Language: Contexts and Consequences. Pacific Grove: Brooks/Cole Publishing Company.

Graddol, David 2006: English Next. British Council. 
Harzing, Anne-Wil/Pudelko, Markus 2013: Language competencies, policies and practices in multinational corporations: A comprehensive review and comparison of Anglophone, Asian, Continental and Nordic MNCs. In Journal of World Business 48, 87-97.

Hellekjær, Glenn Ole/Fairway, Tone 2015: The Mismatch between the Unmet Need and Supply of Occupational English Skills: An Investigation of Higher Educated Government Staff in Norway. In The International Journal of Higher Education Research 70(6), 1033-1050.

Hellekjær, Glenn Ole 2012: A Survey of English Use and Needs in Norwegian Export Firms. In Hermes - Journal of Language and Communication in Business 28, 7-18.

Hellum, Bjørg/Dypedahl, Magne 1998: Business communication and cultural awareness in Norwegian companies. Halden: Østfold distriktshøgskole.

Jenkins, Jennifer/ Cogo, Alessia/ Dewey, Martin 2011: Review of developments in research into English as a Lingua Franca. In Language Teaching 44(3), 281-315.

Kankaanranta, Anne/Louhiala-Salminen, Leena 2018a: ELF in the Domain of Business - BELF: What does the B stand for? In Jenkins, Jennifer/ Dewey, Martin (eds.), The Routledge Handbook of English as a Lingua Franca. Abingdon and New York: Routledge, 309-320.

Kankaanranta, Anne/Karhunen, Päivi/Louhiala-Salminen, Leena 2018b: "English as corporate language” in the multilingual reality of multinational companies. In Multilingua 37(4), 331-351.

Kankaanranta, Anne/ Louhiala-Salminen, Leena/ Karhunen, Päivi 2015: English in Multinational Companies: Implications for Teaching "English" at an International Business School. In Journal of English as a Lingua Franca 4(1), $125-148$.

Kankaanranta, Anne/ Louhiala-Salminen, Leena 2013: “What Language Does Global Business Speak?”: The Concept and Development of BELF. In Ibérica 26, 17-34.

Kankaanranta, Anne/ Louhiala-Salminen, Leena 2010a: 'English? Oh, it's just work!': A Study of BELF users' perceptions. In English for Specific Purposes 29, 204-209.

Kankaanranta, Anne/ Planken, Brigitte 2010b: BELF Competence as Business Knowledge of Internationally Operating Business Professionals. In Journal of Business Communication 47, 380-407.

Karhunen, Päivi/ Kankaanranta, Anne/ Louhiala-Salminen, Leena/ Piekkari, Rebecca 2018: Let's Talk about Language: A Review of Language-Sensitive Research in International Management. In Journal of Management Studies 55(6), 980-1013.

Kassis Henderson, Jane/ Louhiala-Salminen, Leena 2011: Does Language Affect Trust in Global Professional Contexts? Perceptions of International Business Professionals. In Rhetoric, Professional Communication and Globalization 2(1), 15-33.

Kassis Henderson, Jane 2005: Language Diversity in International Management Teams. In International Studies of Management and Organisations 35(1), 66-82.

Komori-Glatz, Miya 2018: Conceptualising English as a Business Lingua Franca. In European Journal of International Management 12(1-2), 44-61.

Kvale, Steinar/Brinkmann, Svend 2009: Interviews: Learning the Craft of Qualitative Research Interviewing ( $2^{\text {nd }}$ ed). Los Angeles, London, New Dehli, Singapore: SAGE.

Lie, Ulf/ Skjoldmo, Sissel 1982: Behov for fremmedspråkkompetanse i nceringslivet. Bergen: Universitetet i Bergen/ Hordaland Lektorlag.

Logemann, Minna/ Piekkari, Rebecca 2015: Localize or local lies? The Power of language and translation in the multinational corporation. In Critical Perspectives on International Business 11(1), 30-53.

Long, Michael H. (ed.) 2005: Second Language Needs Analysis. Cambridge: Cambridge University Press.

Louhiala-Salminen, Leena/ Kankaanranta, Anne 2012: Language as an Issue in International Communication: English or Local Language? If English, what English? In Public Relations Review 38, $262-269$.

Louhiala-Salminen, Leena/ Charles, Mirjaliisa/ Kankaanranta, Anne 2005: English as a Lingua Franca in Nordic corporate mergers: Two case companies. In English for Specific Purposes 24, 401-21.

Marschan-Piekkari, Rebecca/ Welch, Cathrine/ Penttinen, Heli/ Tahvanainen, Marja 2004: Interviewing in the Multinational Corporation: Challenges of the Organizational Context. In Marschan-Piekkari, Rebecca/ Welch, Cathrine (eds.), Handbook of Qualitative Research. Methods for International Business. London: Edward Elgar, 244263.

Mauranen, Anna 2018: Conceptualising ELF. In Jenkins, Jennifer/ Dewey, Martin (eds.), The Routledge Handbook of English as a Lingua Franca. Abingdon and New York: Routledge, 5-24. 
Meierkord, Christiane 2002: 'Language stripped bare' or 'linguistic masala'? Culture in lingua franca communication. In Knapp, Karlfried/ Meierkord, Christiane (eds.), Lingua Franca Communication. Frankfurt am Main: Peter Lang, 109-134.

Neeley, Tsedal B. 2013: Language Matters: Status Loss and Achieved Status Distinctions in Global Organizations. In Organization Science 24(2), 476-497.

Nickerson, Cathrine 2015: The Death of the Non-native Speaker? English as a Lingua Franca in Business Communication: A Research Agenda. In Language Teaching 48(3), 390-404.

Piekkari, Rebecca/ Welch, Denice E./ Welch, Lawrence S. 2014: Language in International Business: The Multilingual Reality of Global Business Expansion. Cheltenham: Edward Elgar

Piekkari, Rebecca/Vaara, Eero/Tienari, Janne/Säntti, Risto 2005: Integration or Disintegration? Human Resources Implications of a Common Corporate Language Decision in a Cross-border Merger. In International Journal of Human Resource Management 16(3), 330-344.

Planken, Brigitte 2005: Managing rapport in lingua franca sales negotiations: A comparison of professional and aspiring negotiators. In English for Specific Purposes 24, 381-400.

Rogerson-Revell, Pamela 2010: “Can You Spell That for Us Non-native Speakers?” Accommodation Strategies in International Business Meetings". In Journal of Business Communication 47, 432-454.

Rogerson-Revell, Pamela 2008: Participation and Performance in International Business Meetings. In English for Specific Purposes 27, 338-360.

Rogerson-Revell, Pamela 2007: Using English for International Business: A European Case Study. In English for Specific Purposes 26, 103-120.

Spencer-Oatey, Helen/ Jiang, Wenying 2003: Explaining cross-cultural pragmatic findings: moving from politeness maxims to sociopragmatic interactional principles (SIPs). In Journal of Pragmatics 35, 1633-1650.

Sweeney, Emma/ Hua, Zhu 2010: Accommodating toward your Audience: Do Native Speakers of English Know How to Accommodate Their Communication Strategies toward Nonnative Speakers of English? In Journal of Business Communication 47(4), 477-504.

Tenzer, Helene/ Terjesen, Siri/ Harzing, Anne-Wil 2017: Language in International Business: A Review and Agenda for Future Research. In Management International Review 57, 815-854.

Welch, Denice/ Welch, Lawrence/ Piekkari, Rebecca 2005: Speaking in Tongues - The Importance of Language in International Management Processes. In International Studies of Management and Organizations 35(1), 10-27. 